\title{
Experimental investigations on heat content of supercooled sodium acetate trihydrate by a simple heat loss method
}

Kong, Weiqiang; Dannemand, Mark; Johansen, Jakob Berg; Fan, Jianhua; Dragsted, Janne; Englmair, Gerald; Furbo, Simon

Published in:
Solar Energy

Link to article, DOI:

10.1016/j.solener.2016.09.045

Publication date:

2016

Document Version

Peer reviewed version

Link back to DTU Orbit

Citation $(A P A)$ :

Kong, W., Dannemand, M., Johansen, J. B., Fan, J., Dragsted, J., Englmair, G., \& Furbo, S. (2016).

Experimental investigations on heat content of supercooled sodium acetate trihydrate by a simple heat loss method. Solar Energy, 139, 249-257. https://doi.org/10.1016/j.solener.2016.09.045

\section{General rights}

Copyright and moral rights for the publications made accessible in the public portal are retained by the authors and/or other copyright owners and it is a condition of accessing publications that users recognise and abide by the legal requirements associated with these rights.

- Users may download and print one copy of any publication from the public portal for the purpose of private study or research.

- You may not further distribute the material or use it for any profit-making activity or commercial gain

- You may freely distribute the URL identifying the publication in the public portal 


\title{
Experimental investigations on heat content of supercooled sodium acetate trihydrate by a simple heat loss method
}

\author{
Weiqiang Kong*, Mark Dannemand, Jakob Berg Johansen, Jianhua Fan, Janne Dragsted, \\ Gerald Englmair, Simon Furbo
}

Technical University of Denmark, Department of Civil Engineering, Kgs. Lyngby 2800, Denmark

\begin{abstract}
Sodium acetate trihydrate is a phase change material that can be used for long term heat storage in solar heating systems because of its relatively high heat of fusion, a melting temperature of $58^{\circ} \mathrm{C}$ and its ability to supercool stable. In practical applications sodium acetate trihydrate tend to suffer from phase separation which is the phenomenon where anhydrous salt settles to the bottom over time. This happens especially in supercooled state. The heat released from the crystallization of supercooled sodium acetate trihydrate with phase separation will be lower than the heat released from sodium acetate trihydrate without phase separation. Possible ways of avoiding or reducing the problem of phase separation were investigated. A wide variety of composites of sodium acetate trihydrate with additives including extra water, thickening agents, solid and liquid polymers have been experimentally investigated by a simple heat loss method. The aim was to find compositions of maximum heat released from the crystallization of supercooled sodium acetate trihydrate samples at ambient temperature. It was found that samples of sodium acetate trihydrate with $0.5 \%$ to $2 \%$ (wt.\%) Carboxy-Methyl Cellulose, $0.3 \%$ to 0.5 $\%$ (wt.\%) Xanthan Gum or 1\% to 2\% (wt.\%) of some solid or liquid polymers as additives had significantly higher heat contents compared to samples of sodium acetate trihydrate suffering from phase separation.
\end{abstract}

Keywords: Sodium acetate trihydrate, Supercooling, Heat content measurement, Phase separation, Phase change material

\section{Introduction}

Solar energy along with other renewable energy sources can play an important role in clean energy utilization in modern society. However, solar energy has the characteristic of being intermittent on a daily basis and has an uneven seasonal distribution. Heat storage is one possible and effective way of solving the mismatch between heat demand and solar energy supply. Solar energy systems combined with long term heat storage are being widely studied in many projects. For example in the four EU funded projects (Helden, 2013) (SAM.SSA, MERITS, SOTHERCO, COMTES), and in IEA SHC Task 42 and IEA ECES Annex 29. Phase change materials (PCMs) are considered as promising heat storage materials due to their latent heat of fusion which can possibly increase storage density compared to 
sensible heat storages. In some PCMs the latent heat of fusion can be preserved without heat loss for a long term storage period via the principle of stable supercooling (Kousksou et al., 2014; Xu et al., 2013; Zalba et al., 2003)

\subsection{Sodium acetate trihydrate as heat storage material}

Sodium acetate trihydrate (SAT), $\mathrm{NaCH}_{3} \mathrm{COO} \cdot 3 \mathrm{H}_{2} \mathrm{O}$, consisting of $60.3 \%$ (wt.\%) sodium acetate and $39.7 \%$ (wt.\%) water, has the ability to supercool stable to ambient temperatures and has relatively high latent heat of fusion of $264 \mathrm{~kJ} / \mathrm{kg}$ at the melting temperature of $58^{\circ} \mathrm{C}$ (Zalba et al., 2003). Once the solidification of the supercooled SAT is activated the latent heat of fusion from the phase change will be released. This energy can be used for space heating and domestic hot water preparation. The ways of activating the solidification are easy and flexible such as cooling a part of the SAT to its maximum degree of supercooling by either evaporating liquid $\mathrm{CO}_{2}$ (Furbo et al., 2012) or by a Peltier element cooling or by mechanically introducing a seed crystal. Therefore SAT is a promising phase change material which can be used for long term heat storage.

Fig. 1(a) shows one sample of supercooled sodium acetate water mixtures which have been in supercooled state for more than 2 years at indoor temperatures. Even impurities such as rusty iron immersed in the supercooled sodium acetate water mixture did not influence the stability of the supercooling, as can be seen in Fig. 1(b).

\subsection{Limitations of the material}

Phase separation/segregation is a key problem of using SAT for heat storage. It causes the heat content of the supercooled SAT to decrease over time (Kimura and Kai, 1985). It is caused by the fact that SAT is an incongruently melting salt hydrate. An incongruently melting salt hydrate consists of an anhydrous salt with corresponding crystal water. The solubility of the anhydrous salt in water, which is given in (Furbo and Svendsen, 1977) is not high enough at the melting point of $58^{\circ} \mathrm{C}$ to dissolve all the

anhydrous salt in the corresponding crystal water of the trihydrate composition. Therefore the molten salt hydrate at a temperature just above the melting point consists of a saturated salt solution and some anhydrous salt undissolved in the water (Kimura and Kai, 1985). When nothing is done to prevent it, the anhydrous salt settles to the bottom of the container as sediment due to its higher density, which can be seen in Fig. 1(a). In supercooled state below the melting point, even less anhydrous salt will be 
dissolved and the problem increases. This can be realized by observing the phase diagram for the sodium acetate - water system (Araki et al., 1995). When the crystallization of a sample is initiated, the anhydrous salt at the bottom is unable to bind with the water in the top of the container. Therefore only a part of the anhydrous salt is active during phase change. The solidified salt hydrate with phase separation consists of three parts: At the bottom the solid salt hydrate crystals with additional anhydrous salt, in the middle a layer of salt hydrate crystals, and at the top the salt hydrate crystals with some additional water in which some salt dissolves in. The amount of sediment increases with repeated cycles, and the heat storage capacity will therefore decrease with each melting/crystallization cycle. Therefore phase separation has to be avoided.

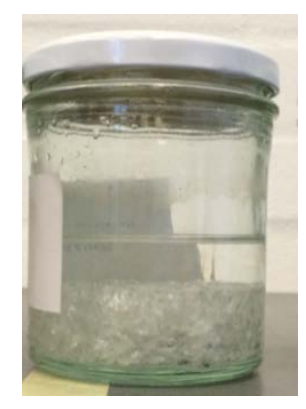

(a)

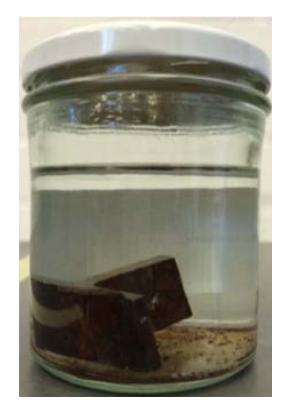

(b)

Fig. 1. Long term supercooled samples of (a) SAT with extra water (b) SAT with extra water and immersed steel

\subsection{Solutions}

Different possible ways of avoiding or reducing phase separation were investigated in previous studies. For example, the problem does not occur for the incongruently melting Glauber's salt, $\mathrm{Na}_{2} \mathrm{SO}_{4} \cdot 10 \mathrm{H}_{2} \mathrm{O}$, if the height of the container is smaller than $0.9 \mathrm{~cm}$ according to Kaufmann (K. Kauffman and Pan, 1972). Glauber's salt has a much larger difference between the salt solubility at the melting point and the content of anhydrous salt in the salt hydrate compared to the difference between the salt solubility at the melting point and the content of anhydrous salt in SAT. Therefore it could be possible that a low material height can avoid phase separation. Adding extra water is suggested a way to avoid phase separation and was studied by Furbo and Svendsen (Furbo and Svendsen, 1977). The stored energy in SAT with extra water has however shown to decrease after a number of cycles in tests with prototype heat storage units with a PCM heights of 5 cm (Dannemand et al., 2015b; Dannemand and Furbo, 2014). Phase separation can also be reduced by adding thickening agents which were 
widely investigated in the literature. Peng Hu et al. (Hu et al., 2011) presented the mixture of SAT with 4 \% Carboxy-Methyl Cellulose (CMC) as thickening agent and 5 \% AIN nanoparticles as nucleating agent which had a high latent heat and avoids the supercooling. Similarly, Garay Ramirez et al. (Garay Ramirez et al., 2013) used 0.5\% AgNPs to reduce the supercooling and mixing silica gel with CMC to avoid phase separation and yielded an increment in the stability of the phase change behaviour. Nearly 95\% of the latent heat of SAT was recovered in this study. In a study by Cabeza et al. (Cabeza et al., 2003), bentonite, starch and Cellulose were investigated for the thickening effect on SAT and they found an enthalpy decrease between 20\% and 35\% depending on the type and amount of thickening agents used. In a study by Ryu et al. (Ryu et al., 1992), a super-absorbent polymer (SAP) made from acrylic acid copolymer and CMC-Na was investigated as thickening agent to avoid phase separation, together with $\mathrm{K}_{2} \mathrm{SO}_{4}$ as the nucleating agents. The combination of SAT with 1\% SAP, 2\% CMC-Na and $2 \% \mathrm{~K}_{2} \mathrm{SO}_{4}$ was used in a study by Choi et al. of heat storage systems (Choi et al., 1996).

Studies (Cabeza et al., 2003; Choi et al., 1996; Garay Ramirez et al., 2013; Haillot et al., 2012, 2011; Hu et al., 2011; Ryu et al., 1992) focused on short term heat storage in which supercooling of the storage materials has to be avoided. Therefore nucleating agents, which reduce the degree of supercooling, were used in those studies. For seasonal heat storage using the principle of stable supercooling, nucleating agents should be avoided and therefore the total mass of the PCM material is reduced. That's one of the advantages of utilizing long term supercooling.

Suggested ways of reducing phase separation can be summarized in the following ways:

- Low height of material

- Adding extra water

- Adding thickening agent

\subsection{Measurement techniques}

Differential thermal analysis (DTA) and differential scanning calorimetry (DSC) methods (Höhne et al., 2003) are conventional method for determining the latent heat of fusion and the specific heat of PCMs. However, DTA and DSC measurement facilities are complicated and expensive and the tested samples are usually very small (1-10 mg), which does not represent the bulk PCMs in actual storages (Zalba et al., 2003). Zhang (Yinping et al., 1999) proposed the T-history method, as a simple alternative to the DTA and DSC methods, to determine the melting point, heat of fusion, specific heat 
and thermal conductivity of the bulk PCMs with additives in a sealed tube. The T-history method was then widely recognized and used in studies. Further modification and improvement for the T-history method were proposed by researchers in order to remove unstable phase change, enhance the measurement accuracy and enlarge the range of applications (Hong et al., 2004, 2003; Peck et al., 2006).

In this study, possible additives for reducing phase separation including extra water, thickening agents, solid and liquid polymers were investigated. Adding extra water will allow for more anhydrous salt to dissolve. Thickening agents can increase the viscosity of the solution and suspend the anhydrous salt in the container so that it does not settle to the bottom of the container. Other solid or liquid additives can work in such a way that the salt solubility is increased so much that phase separation is avoided.

\subsection{The heat loss method}

A simple heat loss method was used to determine the heat contents of supercooled SAT samples by measuring the heat released after the solidification of supercooled SAT samples with and without additives at ambient temperature. The method was designed specifically for measuring heat released from supercooled samples and it resembles the way the material is intended to be used in supercooled thermal energy storage (Dannemand et al., 2016b, 2015c). The results are used for comparison of different combinations of SAT and additives and to find mixtures with high heat contents.

The heat loss method has many advantages compared to conventional test method. First the heat loss method is simple in operation. There are no precision instruments. The equipment is cheap and easy to set up. Second, the bulk samples can be made as the same height as in the applications, for example 5 cm in (Dannemand et al., 2015a). Then the mathematical calculation process is simple. The data logger only records the sample and ambient temperatures. The heat content is easy to calculate. Finally, the well-insulated box provide low and stable heat loss coefficient for the whole test process which is the guarantee for obtaining accurate results. The detailed description can be seen in section 2.1. 


\section{Heat content measurement method}

\subsection{The heat loss test method}

The heat content measurement of SAT samples were carried out by a simple heat loss method. Glass jars with metal lids were used to contain the samples as shown in Fig. 2(a). The glass jars were placed in well insulated boxes to cool down, see Fig. 2(b). There were four boxes tested at the same time. The boxes were located in an underground room where the diurnal temperature variation was minimal.

There were four thermocouple (Type T) temperature sensors for each box. Three of them were fixed outside of glass jar for measuring the temperature of the sample, see Fig. 2(c) and the fourth to measure the ambient temperature nearby.

The temperature sensors were connected to an Agilent data logger and the test data were recorded on a PC. See Fig. 3.

\subsubsection{Determining heat loss coefficient of well insulated boxes}

The main assumption of the method is that the heat loss coefficient $U A(\mathrm{~W} / \mathrm{K})$ of glass jar in the well-insulated box can be determined by having hot water cool down because the properties of water are known. Heated reference samples with water were set to cool down towards the ambient temperature of the room.

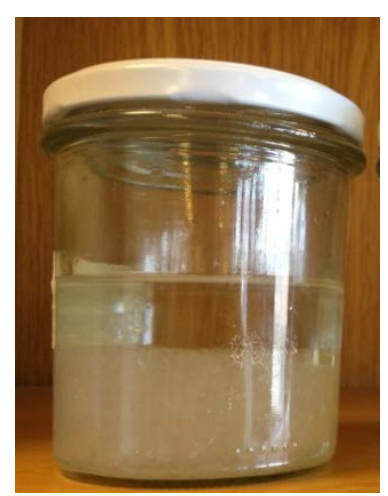

(a)

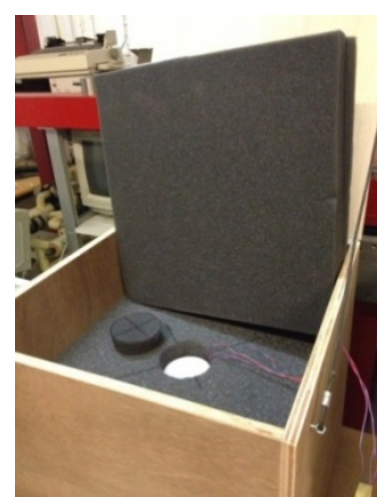

(b)

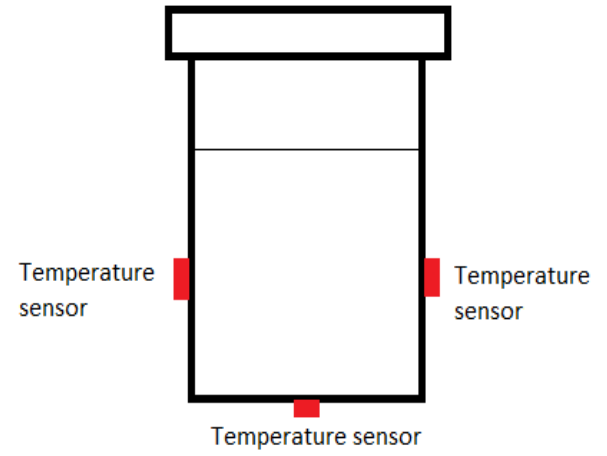

(c)

Fig. 2 (a) Glass jar with lid (b)The well-insulated box (c)Locations of temperature sensors 


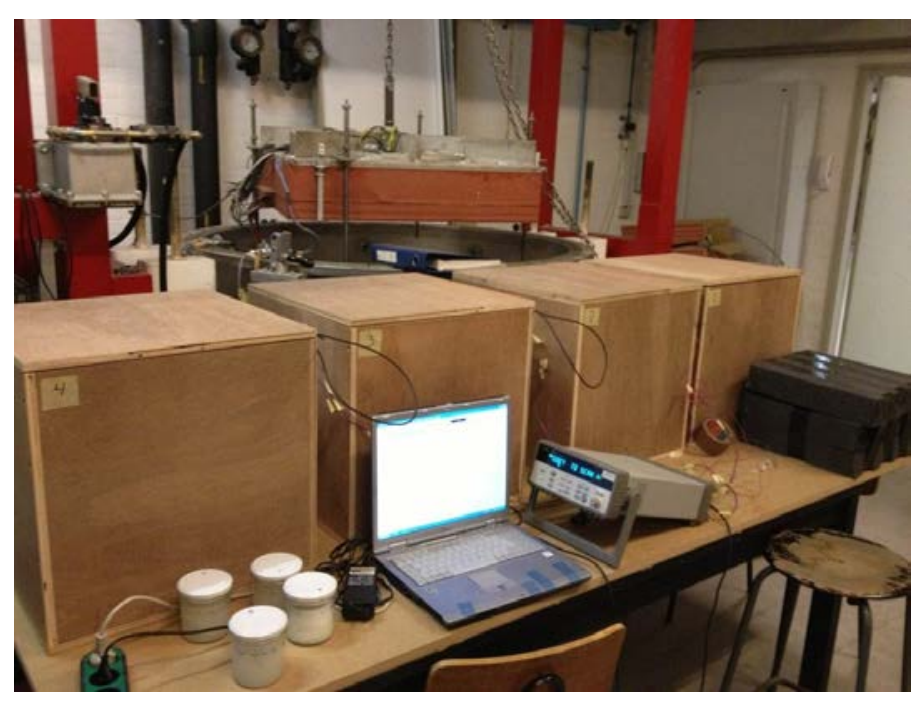

Fig. 3 Test facilities of heat loss test method

The heat loss process of glass jar inside the box can be described by the differential equation of Eq. (1). After solving Eq. (1), a logarithmic equation was derived for calculating $U A$, see Eq. (2).

$$
\begin{gathered}
m c \frac{d T}{d t}=-U A \cdot\left(T-T_{a}\right) \\
U A=\frac{m c}{\Delta t} \ln \frac{T_{e}-T_{a}}{T_{b}-T_{a}}
\end{gathered}
$$

Where $m c(\mathrm{~J} / \mathrm{K})$ is the total heat capacity of the reference consisting of glass, water and lid, $T(\mathrm{~K})$ is water temperature, $T_{b}(\mathrm{~K})$ and $T_{e}(\mathrm{~K})$ are start and end temperature of water, $T_{a}(\mathrm{~K})$ is ambient temperature, $t(\mathrm{~s})$ is time and $\Delta t(\mathrm{~s})$ is time period.

The $U A$ value calculated by Eq. (2) is the average heat loss coefficient of the temperature range from $T_{b}$ to $T_{e}$ during the time interval $\Delta t$. UA values were obtained for all temperature steps, a continuous $U A$ curve was regressed by the scatter of $U A$ values. A quadratic equation described the $U A$ development. Equation for each box was determined. One example is shown in Fig. 4. The blue points are the UA values. Each point was calculated during the time interval of $60 \mathrm{~min}$. The curve was regressed based on $U A$ values and a trend line was obtained with R-square value. The quadratic equation was the UA curve based on reference sample temperatures. 


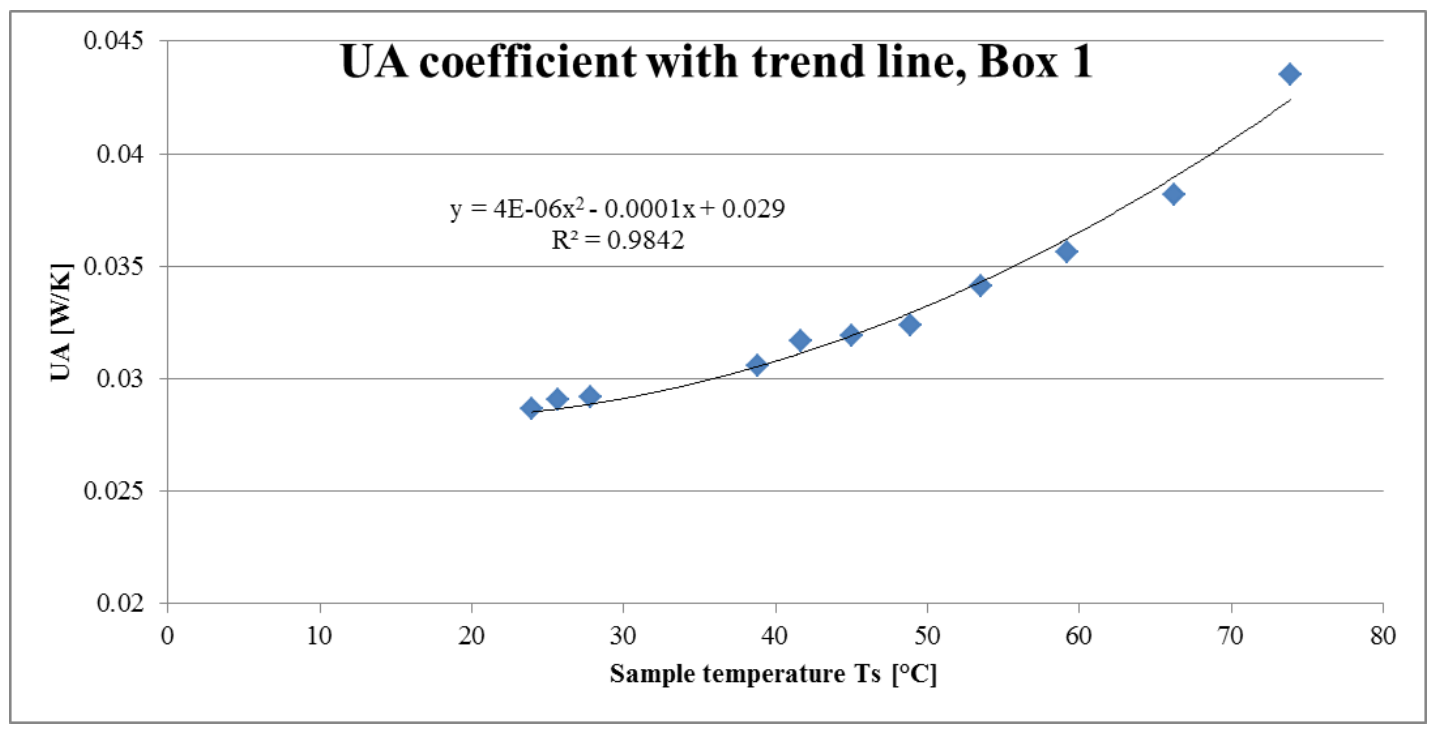

Fig. 4 An example of UA coefficient regression

\subsubsection{Measuring procedure for SAT samples}

The heat released from the supercooled SAT samples after solidification is considered the heat content of the supercooled sample. The heat content of SAT mixtures inside glass jar cooling down after solidification from supercooled state can then be calculated by using the heat loss coefficient $U A$ of the boxes. The heat content measurement procedure of SAT samples can be summarized as follows: 1. The SAT samples were fully melted in the glass jars and then cooled down to the ambient temperature of the room of the test facility leaving them in supercooled state.

2. The samples were placed in the boxes and the solidification was initiated by dropping a SAT crystal into them. The temperature development during the cooling process was recorded. The samples cooled back down to the ambient temperature of the test facility room.

3. The heat contents $E(\mathrm{~kJ} / \mathrm{kg})$ of the SAT samples were determined by using the heat loss coefficient and the recorded temperatures. See Eq. (3), where $T_{s}$ is the SAT sample average temperature, $m$ is the mass of the SAT sample.

$$
E=\int_{t}^{t+\Delta t} U A(t) \cdot\left[T_{s}(t)-T_{a}(t)\right] \cdot d t / m
$$

Fig. 5 shows the temperature development of a SAT sample cooling down to ambient temperature to supercooled state followed by activation of solidification, the rapid increase in temperature and the 
cooling down to ambient temperature again. The green area is the heat content measured by this heat loss method.

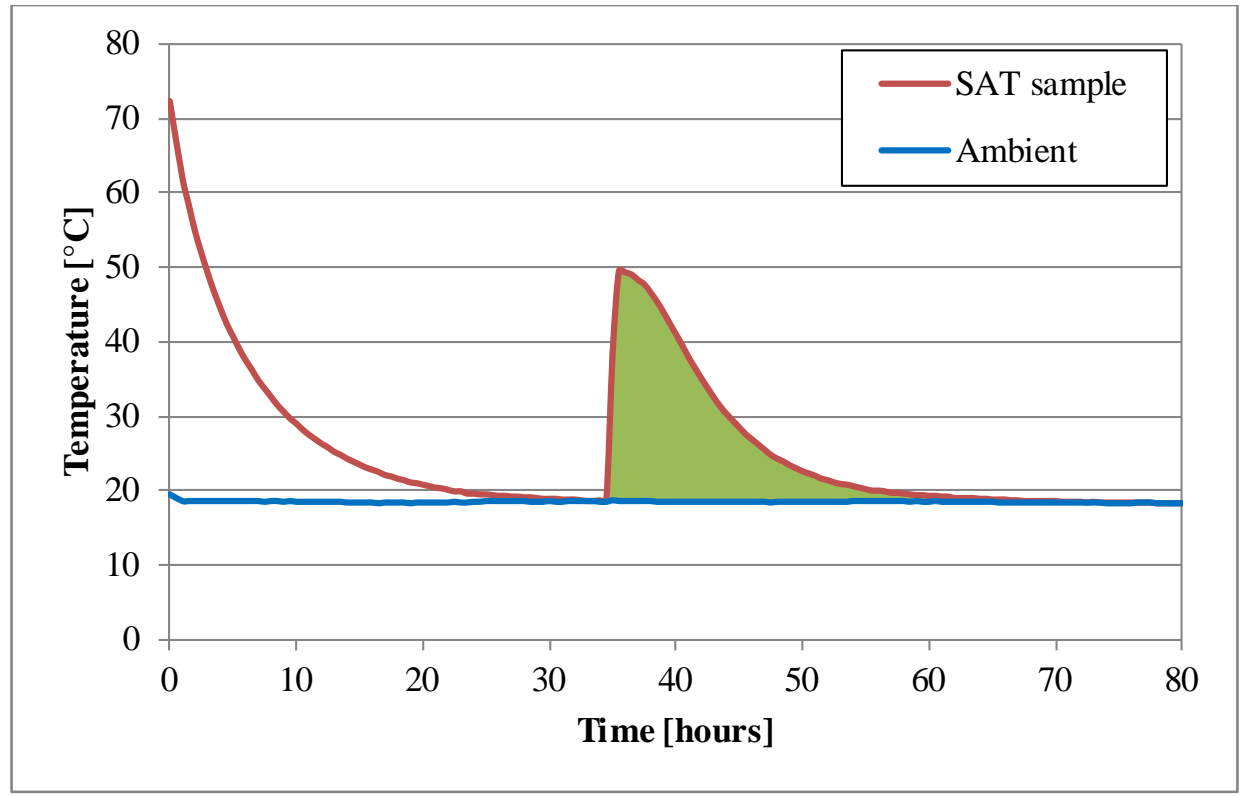

Fig. 5 An example of cooling process of PCM

The heat loss method is closely related to the T-history method but not the same. The T-history method compares the cooling or heating over time of a water sample as a reference and the investigated sample simultaneously. Whereas the heat loss method uses a water sample as a reference to determine the heat loss coefficient of a well-insulated box. Afterwards the investigated sample is then placed in the box to cool down. This heat loss coefficient used to calculate the heat released from the investigated sample and thereby determine its heat content.

\subsection{Materials}

Possible additives for reducing phase separation including extra water, thickening agents, solid and liquid polymers are investigated. The masses of additives in the following paragraphs are given in weight percentages.

The following materials were used:

Sodium acetate trihydrate (analytical degree, purity>99\%) produced by Shijiazhuang Haosheng Chemical Co. Ltd in China.

A variety of additives were tested including, 
- Thickening agents provided as samples by the company of CP Kelco

o Carboxymethyl Cellulose (CMC) under the product name CEKOL ${ }^{\circledR} 30000$

o Xanthan Gum (X-Gum) under the product name Keltrol ${ }^{\circledR}$ Advance Performance

The thickening agents CMC and X-Gum are widely used in the food industry. The thickening effect can increase the viscosity of the SAT and suspend the anhydrous salt in the container so that phase separation is reduced or avoided.

A selection of other additives with various effects on the phase separation was investigated. Effect on some of the additives could be to increase the solubility of anhydrous sodium acetate in crystal water.

- Acid modifier, tartaric acid (CAS number: 526-83-0);

- Glycerol $\left(\mathrm{C}_{3} \mathrm{H}_{5}(\mathrm{OH})_{3}\right)$ (CAS number: 56-81-5);

- Chelating agent, EDTA. Disodium Ethylenediaminetetraacetic acid (CAS number: 139-333);

- Solid polymer AMPS. 2-Acrylamido-2-methylpropane sulfonic acid (CAS number: 1521489-8);

- AquaKeep (10SH-NF) produced by SUMITOMO SEIKA Chemicals Co., Ltd.

- Liquid polymers HD 200 (PH: 4.5), HD 310 (PH: 4.0) and HD 500 (PH: 4.0) are liquid polymers with different lengths of molecular chains provided by Suzhou Hongde Co., Ltd. Jiangsu, China.

\subsection{Sample preparation}

The heat content measurements were carried out with SAT and three types of additives; (1) different quantities of extra water, (2) thickening agents and (3) polymer additives. All the samples were prepared with a height of $5 \mathrm{~cm}$ in liquid phase. All heat content results $(\mathrm{kJ} / \mathrm{kg})$ were calculated by considering the total mass of SAT including additives. The water used in experiments was distilled water.

SAT contains approximately $40 \%$ water. Samples of sodium acetate water mixtures with the water content of 40\% (205g SAT), 42\% (196g SAT+7.8g water), 45\% (185g SAT+17.8g water) and 46\% $(180 \mathrm{~g}$ SAT+21g water) were prepared. Three repetitions of each sodium acetate water mixture, in total of 12 samples were made. 
Samples of $200 \mathrm{~g}$ SAT with $0.1 \%$ to $2 \%$ CMC and Xanthan Gum were prepared. A proper mixing method was necessary for adding thickening agents into the SAT, especially Xanthan Gum. The Xanthan Gum powder binds very fast with the water when it is mixed into a sample and will easily form jelly chunks in the sample instead of dispersing evenly in the sample. To achieve uniformly mixed samples $90 \%$ of the SAT was melted in an oven, the remaining $10 \%$ of the SAT was in cold solid granular state mixed with the thickening agent powder before it was added to the melted SAT little by little while mixing with an overhead stirrer. Mixing at hot state will easily trap unwanted air bobbles inside the mixture therefore the mixing was done carefully to avoid this (Dannemand et al., 2016a).

Samples of $200 \mathrm{~g}$ SAT with different quantities of liquid or solid polymers were prepared. The liquid or solid polymers were added little by little into the melted SAT while stirring with an electronic stirrer.

\subsection{Relating of the latent heat of fusion to the heat content}

The heat content of a supercooled SAT sample is defined in this paper as the thermal energy dispersed to the ambient environment by the natural cooling process towards the ambient temperature after solidification of the supercooled SAT sample at ambient temperature (The green area in Fig. 5).

The definition of the latent heat of fusion is the enthalpy change resulting from heating a given quantity of a substance to change its state from a solid to a liquid at the temperature of the melting point (G.F.S., 1922).

The latent heat of fusion at the melting point is therefore somewhat different but related to the heat content of a supercooled sample. The heat loss method measures the heat content.

The following theory (Dannemand and Furbo, 2014) explains the theoretical heat content of SAT in a simplified way as if the SAT behaves as an ideal compound which changes from solid to liquid phase at a specific melting temperature.

Eq. (4) and Eq. (5) show the theoretical change of thermal energy over a temperature increase where the melting temperature is passed for a heating and a cooling process.

$$
\begin{gathered}
E_{\text {heating }}=\left(T_{\text {melt }}-T_{\text {start }}\right) \cdot c_{p}(s)+L+\left(T_{\text {max }}-T_{\text {melt }}\right) \cdot c_{p}(l) \\
E_{\text {cooling }}=\left(T_{\text {max }}-T_{\text {melt }}\right) \cdot c_{p}(l)+L+\left(T_{\text {melt }}-T_{\text {end }}\right) \cdot c_{p}(s)
\end{gathered}
$$

where $T_{\text {melt }}$ is the melting point of $58^{\circ} \mathrm{C}, T_{\text {start }}$ is the PCM temperature at the start of the charge, $c_{p}(S)$ is the specific heat of SAT in solid phase, $c_{p}(l)$ is the specific heat of SAT in liquid phase, $L$ is the heat of 
fusion, $T_{\max }$ is the maximum temperature of the PCM during heating, $T_{\text {end }}$ is the temperature of the PCM after the cooling.

When the SAT cools down to $T_{\text {end }}$ without crystalizing, assuming that the specific heat of the supercooled SAT has the same properties as the liquid SAT, then the stored thermal energy in the supercooled PCM is:

$$
E_{\text {supercooled }}=E_{\text {heating }}-c_{p}(l) \cdot\left(T_{\max }-T_{\text {end }}\right)
$$

If $T_{\text {start }}$ and $T_{\text {end }}$ are equal, then $E_{\text {heating }}$ and $E_{\text {cooling }}$ are also equal. When the temperature of the supercooled SAT and the end temperature are the same, then the thermal energy stored at supercooled state is:

$$
E_{\text {supercooled }}=L-\left(T_{\text {melt }}-T_{\text {end }}\right) \cdot\left[\mathrm{c}_{p}(l)-c_{p}(s)\right]
$$

The heat content measured by the heat loss method is theoretically equal to $E_{\text {supercooled }}$ which is lower than the heat of fusion. $E_{\text {supercooled }}$ can be calculated according to Eq. (7). Assuming that $T_{\text {end }}$ is $20{ }^{\circ} \mathrm{C}$,

the latent heat of fusion is $264 \mathrm{~kJ} / \mathrm{kg}$, the specific heat capacity $c_{p}(l)$ and $c_{p}(\mathrm{~s})$ are $2.8 \mathrm{~kJ} /(\mathrm{kg} \cdot \mathrm{K})$ and 1.9 $\mathrm{kJ} /(\mathrm{kg} \cdot \mathrm{K})$, respectively (Araki et al., 1995). In reality the specific heat capacities are temperature dependant but for this calculations average values over the representative intervals are used. The theoretical heat content of SAT at $20^{\circ} \mathrm{C}$ is calculated to $230 \mathrm{~kJ} / \mathrm{kg}$. The heat content at the supercooled state is lower than the latent heat of fusion due to the different heat capacities of the liquid and the solid state of the material and depends on the supercooled and end temperature of the SAT sample.

\subsection{Error analysis}

The deviation between measured heat content and the theoretical heat content mainly comes from two parts.

The first is from the change of ambient temperature. During one test, the variation of ambient temperature was within $0.5 \mathrm{~K}$ but among all the tests the maximum difference of ambient temperature was up to $7 \mathrm{~K}$. Assuming that $c_{p}(l)$ is the specific heat capacity of the supercooled SAT and $c_{p}(s)$ is the specific heat capacity of SAT in solid state and the two heat capacities are constant when the ambient temperature changes $7 \mathrm{~K}$. The theoretical heat content is $230 \mathrm{~kJ} / \mathrm{kg}$. The relative error of this term can be estimated as

$$
\frac{\Delta Q}{E}=\frac{\left[c_{p}(l)-c_{p}(s)\right] \Delta T_{\text {end }}}{E}=\frac{(2.8-1.9) \cdot 7}{230}=2.3 \%
$$


The second deviation comes from the temperature measurement method. The average temperature of three temperature sensors fixed outside of glass jar for representing the sample temperature was lower than the actual material temperature. The error can be estimated by the Biot number (Bi) for long cylinder heat exchange object which is shown in Eq. (9), in which $h\left(\mathrm{~W} / \mathrm{m}^{2} \cdot \mathrm{K}\right)$ is the surface heat loss coefficient, $R$ is the cylinder diameter and $\lambda(\mathrm{W} / \mathrm{m} \cdot \mathrm{K})$ is the thermal conductivity of SAT-additives. $h$ can be calculated by $U A A_{s}$, where $A_{s}$ is the surface area. Since $U A$ is a function of temperature varying around $0.029-0.035$ from $20^{\circ} \mathrm{C}$ to $55^{\circ} \mathrm{C}$ and $\lambda$ has a value from literature with large variations 0.17 1.1(Dannemand et al., 2016a), the Biot number can be calculated as a range of 0.04-0.34 which is shown in Eq. (9). In theory, only if the Biot number is smaller than 0.05, the outside average temperature can represent the whole sample temperature (Yang and Tao, 1998).

$$
B i=\frac{h R}{2 \lambda}=\frac{U A / A_{s} \cdot R}{2 \lambda}=\frac{(0.029 \sim 0.034) / 0.01 \cdot 0.034}{2(0.17 \sim 1.1)}=0.04 \sim 0.34
$$

\section{Results and discussion}

The heat contents measured by the simple heat loss method for samples of SAT with extra water, SAT with thickening agents and SAT with polymer additives are presented in the following subsections. All results are shown as specific heat content. The masses used in calculations are for total PCM mass including SAT and additives.

\subsection{Heat content measurement of SAT with extra water}

The $40 \%, 42 \%, 45 \%$ and $46 \%$ water content SAT-water samples were tested with different durations of the supercooled period: Less than 14 days, 41 days and 100 days. The tests with the period of less than 14 days were repeated three times. Fig. 6 shows the samples after 100 days of supercooling. It can be seen from the figure that both the $40 \%$ and $42 \%$ samples have a visible salt crystal layer at the lower part of the sample. The crystal layer of the $42 \%$ sodium acetate water mixture appeared looser compared to the $40 \%$ mixture. Both the mixtures of $45 \%$ and $46 \%$ were transparent without any visible segregation. 


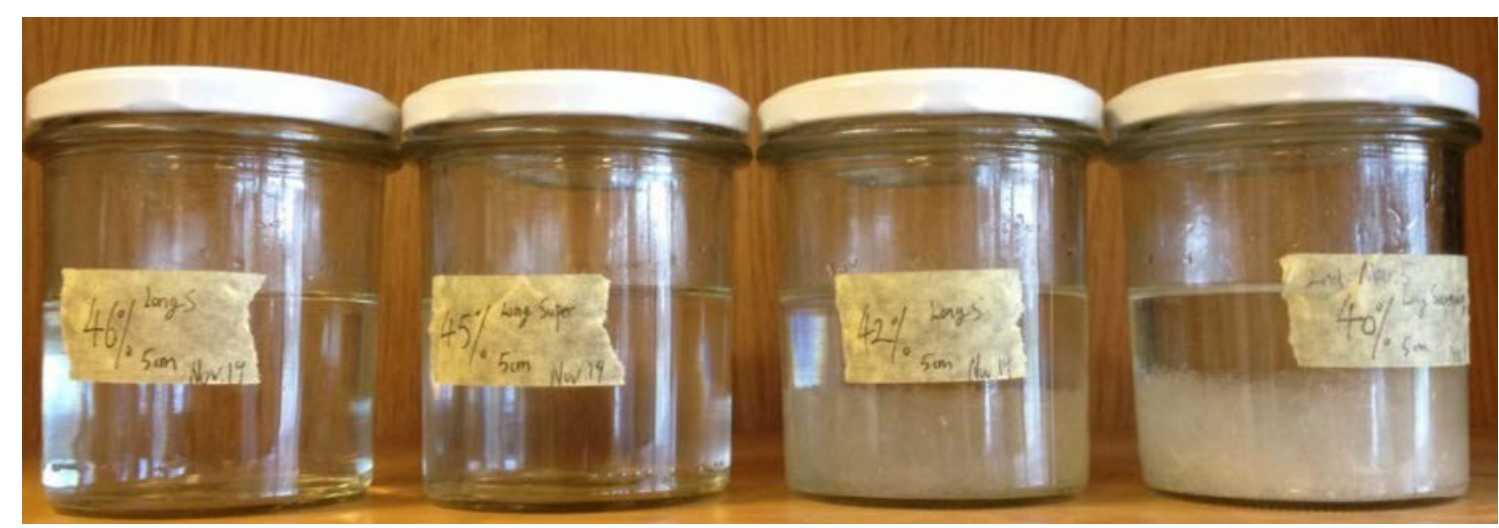

Fig. 6 The 40\%, 42\%, 45\% and 46\% salt water mixtures from right to left after 100 days supercooling

The measured heat contents are plotted in Fig. 7. It can be seen from the figure that:

- For the short supercooled periods, the $42 \%$ mixture had the highest heat content of $194 \mathrm{~kJ} / \mathrm{kg}$.

- With a supercooled period of 41 days, the heat content for the $42 \%$ mixture was reduced to $162 \mathrm{~kJ} / \mathrm{kg}$, while the heat content for the other mixtures were almost the same as for the short supercooled periods.

- For the samples which were supercooled for 100 days, the heat content of both the $40 \%$ and $42 \%$ mixtures were lower than for the short supercooled period. The heat content of the $45 \%$ and $46 \%$ mixtures were not further decreased.

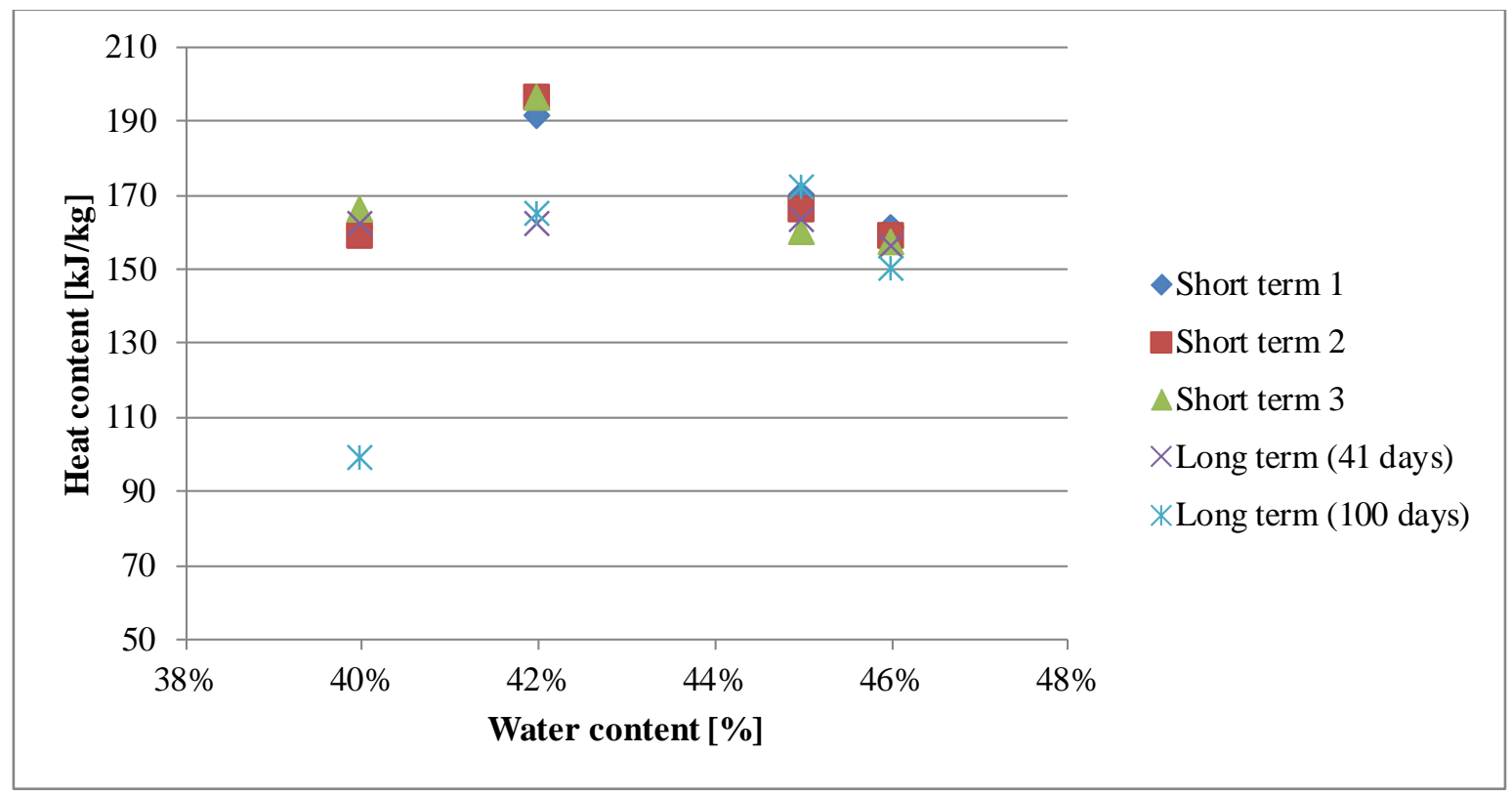

Fig. 7 Heat content of the $40 \%, 42 \%, 45 \%$ and $46 \%$ water salt mixtures 


\subsection{Heat content measurement of SAT with thickening agent}

Table 1 and Table 2 show the measured heat content for SAT with different quantities of Xanthan Gum and CMC. All the samples were tested after short term supercooling period - less than 7 days. The heat content of SAT with $0.1 \%$ and $0.2 \%$ Xanthan Gum was $183-195 \mathrm{~kJ} / \mathrm{kg}$. SAT samples with $0.3 \%$ $0.5 \%$ Xanthan Gum had the highest heat contents with an average of $214 \mathrm{~kJ} / \mathrm{kg}$. Samples with $1 \%$ to $2 \%$ Xanthan Gum had heat contents of 204-208 kJ/kg.

The heat contents of SAT with CMC were for all mixtures above $200 \mathrm{~kJ} / \mathrm{kg}$. Samples with $0.3 \%$ and $2 \%$ CMC had heat contents of 213-216 kJ/kg which was a slight improvement compared to SAT with $0.1 \%$ to $0.2 \%$ CMC.

Table 1. Heat content of SAT with different quantities of Xanthan Gum

\begin{tabular}{|c|c|c|c|c|c|c|c|c|c|}
\hline \multirow[b]{2}{*}{ SAT } & \multicolumn{4}{|c|}{ Heat content $(\mathrm{kJ} / \mathrm{kg})$} & \multirow{2}{*}{ SAT } & \multicolumn{4}{|c|}{ Heat content $(\mathrm{kJ} / \mathrm{kg})$} \\
\hline & Test 1 & Test 2 & Test 3 & Average & & Test 1 & Test 2 & Test 3 & Average \\
\hline$+0.1 \%$ X-Gum & 179 & 185 & 184 & 183 & $+0.5 \%$ X-Gum & 213 & 216 & 214 & 214 \\
\hline$+0.2 \%$ X-Gum & 196 & 196 & 192 & 195 & $+1.0 \%$ X-Gum & 205 & 214 & 205 & 208 \\
\hline + 0.3\% X-Gum & 213 & 217 & 214 & 215 & $+1.5 \%$ X-Gum & 205 & 208 & 204 & 206 \\
\hline$+0.4 \%$ X-Gum & 210 & 217 & 215 & 214 & $+2.0 \%$ X-Gum & 208 & 206 & 206 & 207 \\
\hline
\end{tabular}

Table 2. Heat content of SAT with different quantities of CMC

\begin{tabular}{|c|c|c|c|c|c|c|c|c|c|}
\hline \multirow{2}{*}{ SAT } & \multicolumn{4}{|c|}{ Heat content $(\mathrm{kJ} / \mathrm{kg})$} & \multirow{2}{*}{ SAT } & \multicolumn{4}{|c|}{ Heat content $(\mathrm{kJ} / \mathrm{kg})$} \\
\hline & Test 1 & Test 2 & Test 3 & Average & & Test 1 & Test 2 & Test 3 & Average \\
\hline$+0.1 \% \mathrm{CMC}$ & 194 & 201 & 206 & 200 & $+0.5 \% \mathrm{CMC}$ & 208 & 210 & 217 & 212 \\
\hline$+0.2 \% \mathrm{CMC}$ & 208 & 212 & 209 & 210 & $+1.0 \%$ CMC & 209 & 212 & 211 & 211 \\
\hline$+0.3 \% \mathrm{CMC}$ & 210 & 215 & 214 & 213 & $+1.5 \%$ CMC & 211 & 213 & 214 & 213 \\
\hline$+0.4 \%$ CMC & 216 & 216 & 207 & 213 & $+2.0 \% \mathrm{CMC}$ & 219 & 215 & 215 & 216 \\
\hline
\end{tabular}

It needs to be noted that the thickening agents did not work together with extra water. When extra water was added, the thickening agents had no effect of increasing heat content because extra water has the dilution effect. Table 3 illustrates the phenomenon which shows the heat content of $42 \%$ SAT-water mixtures with $0.1 \%$ to $0.4 \%$ CMC. The average heat content was around $190 \mathrm{~kJ} / \mathrm{Kg}$ which was similar to the heat content of $42 \%$ salt water mixture without additives and far below the heat content of SAT with $0.1 \%$ to $0.4 \%$ CMC. This shows that for the short test periods there is no phase separation occurring in the $42 \%$ samples and the thickening agent therefore has no effect. In longer test periods the thickening agent may help to avoid decrease in heat content as reported in Fig 7. 
Table 3 . Heat contents of $42 \%$ water content salt water mixture with $0.1 \%$ to $0.4 \%$ CMC

\begin{tabular}{lcccc}
\hline \multirow{2}{*}{$\begin{array}{l}\text { 42\% water content } \\
\text { salt water mixture }\end{array}$} & \multicolumn{4}{c}{ Heat content (kJ/kg) } \\
\cline { 2 - 5 } & Test 1 & Test 2 & Test 3 & Average \\
\hline$+0.1 \%$ CMC & 198 & 200 & 186 & 195 \\
$+0.2 \%$ CMC & 187 & 193 & 192 & 191 \\
$+0.3 \%$ CMC & 189 & 191 & 187 & 189 \\
$+0.4 \%$ CMC & 188 & 189 & 195 & 191 \\
\hline
\end{tabular}

\subsection{Heat content measurement of SAT with polymer additives}

Through heat content experiments, it was found that glycerol, AquaKeep and tartaric acid had limited effect on increasing the heat content of SAT-additive mixtures, see Table 4. All the samples were tested after short term supercooling period - less than 7 days. The heat content of SAT-glycerol, SAT-AquaKeep and SAT-tartaric was up to $164 \mathrm{~kJ} / \mathrm{kg}, 201 \mathrm{~kJ} / \mathrm{kg}$ and $185 \mathrm{~kJ} / \mathrm{kg}$, respectively.

Table 4. Heat content of SAT with different quantities of Glycerol, Aquakeep and Tartaric acid

\begin{tabular}{llll}
\hline SAT & Heat content $(\mathrm{kJ} / \mathrm{kg})$ & SAT & Heat content $(\mathrm{kJ} / \mathrm{kg})$ \\
\hline$+1 \%$ Glycerol & 161 & $+1.5 \%$ Aquakeep $+3 \% \mathrm{H}_{2} \mathrm{O}$ & 192 \\
$+2 \%$ Glycerol & 161 & $+2 \%$ Aquakeep $+3 \% \mathrm{H}_{2} \mathrm{O}$ & 201 \\
$+2 \%$ Glycerol $+1 \% \mathrm{H}_{2} \mathrm{O}$ & 162 & $+1 \%$ Tartaric acid & 166 \\
$+3 \%$ Glycerol $+1 \% \mathrm{H}_{2} \mathrm{O}$ & 164 & $+2 \%$ Tartaric acid & 172 \\
$+0.5 \%$ Aquakeep & 191 & $+1 \%$ Tartaric acid $+4 \% \mathrm{H}_{2} \mathrm{O}$ & 185 \\
$+1 \%$ Aquakeep & 193 & $+2 \%$ Tartaric acid $+2 \% \mathrm{H}_{2} \mathrm{O}$ & 176 \\
$+0.5 \%$ Aquakeep $+2 \% \mathrm{H}_{2} \mathrm{O}$ & 188 & $+2 \%$ Tartaric acid $+6 \% \mathrm{H}_{2} \mathrm{O}$ & 162 \\
$+1 \%$ Aquakeep $+3 \% \mathrm{H}_{2} \mathrm{O}$ & 201 & $+4 \%$ Tartaric acid $+6 \% \mathrm{H}_{2} \mathrm{O}$ & 166 \\
\hline
\end{tabular}

On the other hand, the solid additives EDTA, AMPS and the liquid polymer HD 200, HD 310 and HD 500 significantly increased the heat content of SAT-additive mixtures compared to SAT without additives. Typically an increase of $30 \%$ of heat content was observed. Through the heat content experiments with different compositions of SAT and additive mixtures it was found that SAT with 1\% to $2 \%$ polymer additives had high heat contents of up to $216 \mathrm{~kJ} / \mathrm{kg}$. The promising polymer additives and the results are listed in Table 5. It can be seen from Table 5 that the heat contents of all the SATadditive combinations were above $200 \mathrm{~kJ} / \mathrm{kg}$. Some samples of SAT with EDTA or HD had heat contents even higher than $210 \mathrm{~kJ} / \mathrm{kg}$. 
Table 5 . Heat contents of SAT with $1 \%$ or $2 \%$ polymer additives

\begin{tabular}{ccccc}
\hline \multirow{2}{*}{ SAT } & \multicolumn{4}{c}{ Heat content (kJ/kg) } \\
\cline { 2 - 5 } & Test 1 & Test 2 & Test 3 & Average \\
\hline+ 1\% EDTA & 214 & 215 & 218 & 216 \\
+ 2\% EDTA & 213 & 212 & 221 & 215 \\
+ 1\% AMPS & 205 & 207 & 206 & 206 \\
+ 2\% AMPS & 205 & 204 & 205 & 205 \\
+ 2\% HD 200 & 217 & 216 & 216 & 216 \\
+ 2\% HD 310 & 215 & 215 & 217 & 216 \\
+ 2\% HD 500 & 212 & 212 & 215 & 213 \\
\hline
\end{tabular}

Table 6 shows the heat contents of SAT with polymer additives and extra water. It can be seen from the table that the samples of SAT with polymer additives and extra water had lower heat contents than the samples of SAT with polymer additives in Table 5 but higher heat content compare to samples of SAT with phase separation and SAT with extra water.

Table 6. Heat contents of SAT with polymer additives with extra water

\begin{tabular}{lccc}
\hline \multirow{2}{*}{ SAT } & \multicolumn{3}{c}{ Heat content $(\mathrm{kJ} / \mathrm{kg})$} \\
\cline { 2 - 4 } & Test 1 & Test 2 & Test 3 \\
\hline +3\% EDTA + 4\% H2O & 203 & 203 & - \\
$+3 \%$ AMPS + 2\% H2O & 197 & 200 & 196 \\
$+2.6 \%$ HD200 +1.7\% H2O & 200 & 198 & 200 \\
$+2 \%$ HD310 +1.9\% H2O & 200 & 199 & 201 \\
$+2.6 \%$ HD500 +1.5\% H2O & 203 & 200 & 2 \\
\hline
\end{tabular}

\subsection{Discussion}

Fig. 8 gives an overview of all results of heat content ranges for the SAT samples with different additives. The first column is the heat content of SAT suffering from phase separation, followed by SAT with extra water, thickening agents CMC and X-Gum, and the solid and liquid additives presented in section 2.1. Each column represents the heat contents of the tested samples. The blue part of the column is the lowest heat content and the red part is the measured heat content fluctuation which was caused by different quantities of additives in SAT. 


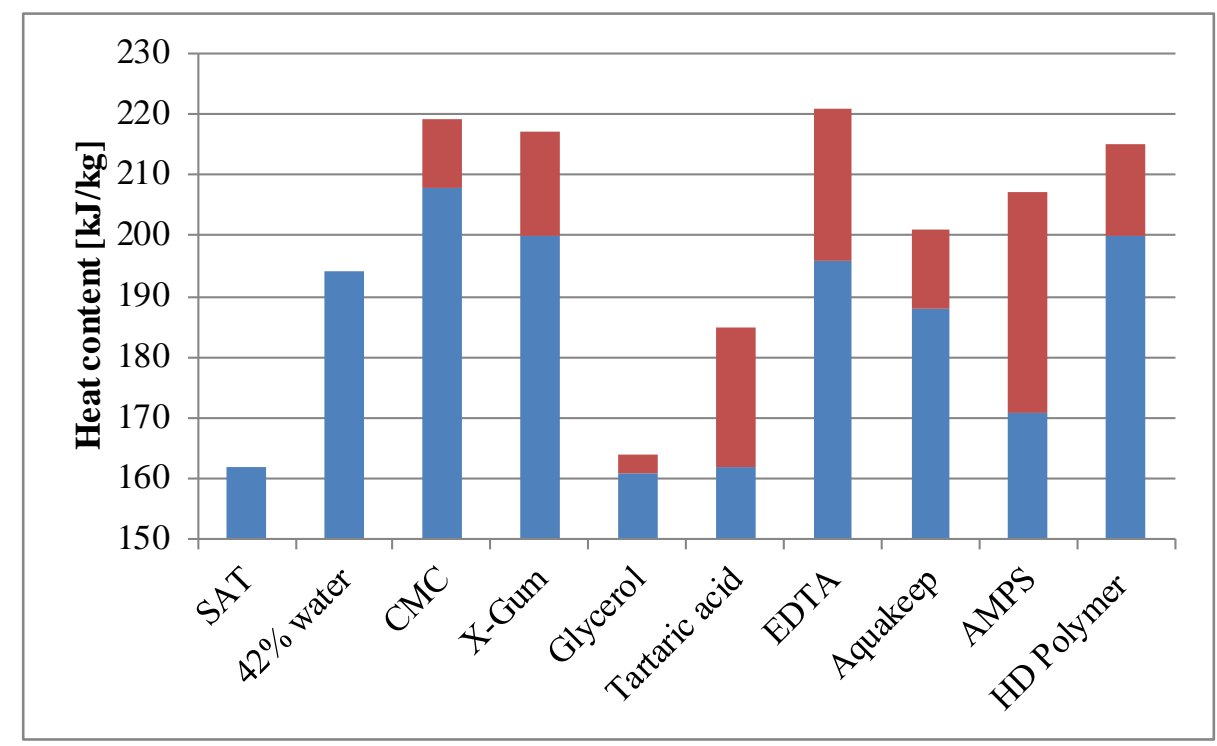

Fig. 8 Full scope of measured heat contents of SAT with and without different additives

Adding extra water into SAT is the easiest way to reduce phase separation since all the sodium acetate can be dissolved in water. However, in comparison of results it can be seen that the heat content of SAT-water (up to $194 \mathrm{~kJ} / \mathrm{kg}$ ) was lower compared to other SAT-additive compositions.

Adding thickening agents into SAT is an effective way of reducing phase separation by increasing the viscosity of SAT solution. There was a trend that for increased quantities of additives, the measured heat content increased. However, too large quantities of the additives will significantly increase the viscosity of the heat storage material and solid materials may be difficult to fully melt during the heating process, especially for SAT with Xanthan Gum. In addition, the specific heat content will be reduced by large quantities of additive and increasing material cost is another concern.

The solid and liquid polymer materials also showed to increase the heat content of SAT-polymer mixtures but the working principle is not clear. They do not increase the viscosity of the PCM as the thickening agents does. One theory is that the polymer materials increase the solubility of anhydrous sodium acetate in the water and in such a way that phase separation is avoided. Another theory could be that the chelating effect such as EDTA performs which may "keep" anhydrous salt dissolved in the solution by its hexadentate (“six-toothed”) structure resulting in an increased solubility.

The comparison of heat content of SAT with thickening agents and extra water shown in Table 3 and heat content of SAT with polymer additives and extra water shown in Table 6 also verified that the 
working principle of increasing the heat content of SAT-additive mixture is different by the two kinds of additives.

\section{Conclusions}

The heat content measurements for samples of SAT with different additives with a height of $5 \mathrm{~cm}$ in liquid phase have been carried out in order to elucidate how best to reduce the phase separation and maximize the heat content for SAT composites in supercooled state.

The theoretical heat content of supercooled SAT at $20^{\circ} \mathrm{C}$ was calculated to be $230 \mathrm{~kJ} / \mathrm{kg}$ by applying the latent heat of fusion of $264 \mathrm{~kJ} / \mathrm{kg}$, the liquid and solid SAT specific heat capacity of $2.8 \mathrm{~kJ} /(\mathrm{kg} \cdot \mathrm{K})$ and $1.9 \mathrm{~kJ} /(\mathrm{kg} \cdot \mathrm{K})$. Based on heat content measurements the heat released after solidification of a supercooled sample of SAT without additives was $162 \mathrm{~kJ} / \mathrm{kg}$. The lower value is due to the phase separation in the SAT.

For samples of SAT and extra water, the highest measured heat content was $194 \mathrm{~kJ} / \mathrm{kg}$ which was obtained in $42 \%$ water content salt water mixture. It was found that SAT and SAT-water mixtures with water contents lower than or equal to $42 \%$ suffered from phase separation. SAT-water mixtures with water contents higher than $42 \%$ did not suffer from the phase separation under the tested conditions. However, the heat content of SAT-water mixtures was decreased by the extra water and by a long supercooled period.

Adding thickening agent was an efficient way to reduce phase separation and thereby increased the energy released from heat storage material. SAT with 0.5\%-2\% CMC and SAT with 0.3\% to 0.5\% Xanthan Gum properly dispersed in the sample are promising seasonal heat storage materials which had the heat content of about 30\% higher than SAT with phase separation. Experiments showed that the heat contents of the above mentioned compositions were higher than $210 \mathrm{~kJ} / \mathrm{kg}$ and up to $216 \mathrm{~kJ} / \mathrm{kg}$.

The solid polymer materials EDTA and AMPS and the liquid polymer material HD series are also potential additives for SAT based heat storage materials since the SAT-polymer compositions had high heat contents above $200 \mathrm{~kJ} / \mathrm{kg}$ and they were also working with extra water. The heat contents of SAT with $1 \%$ to $2 \%$ EDTA, AMPS, HD polymers were between $205-216 \mathrm{~kJ} / \mathrm{kg}$.

All in all, the optimal SAT and additive composite should be carefully selected and tested for cycling stability in order to find the best performing SAT composite for heat storage applications. 


\section{ACKNOWLEDGEMENT}

This project was co-funded by the European Commission as part of the Seventh Framework Programme of the European Community for Research, Technological Development and Demonstration Activities under the funding scheme of “Collaborative Project” through the COMTES consortium and H.M. Heizkörper GmbH \& Co. KG.

\section{References}

Araki, N., Futamura, M., Makino, A., Shibata, H., 1995. Measurements of thermophysical properties of sodium acetate hydrate. Int. J. Thermophys. 16, 1455-1466.

Cabeza, L.F., Svensson, G., Hiebler, S., Mehling, H., 2003. Thermal performance of sodium acetate trihydrate thickened with different materials as phase change energy storage material. Appl. Therm. Eng. 23, 16971704. doi:10.1016/S1359-4311(03)00107-8

Choi, J.C., Kim, S.D., Han, G.Y., 1996. Heat transfer characteristics in low-temperature latent heat storage systems using salt-hydrates at heat recovery stage. Sol. Energy Mater. Sol. Cells 40, 71-87. doi:10.1016/0927-0248(95)00084-4

Dannemand, M., Dragsted, J., Fan, J., Johansen, J.B., Kong, W., Furbo, S., 2015a. Experimental investigations on prototype heat storage modules utilizing stable supercooling of sodium acetate trihydrate mixtures. Appl. Energy 169, 72-80. doi:10.1016/j.apenergy.2016.02.038

Dannemand, M., Furbo, S., 2014. Test of thermobattrie heat storage module. Report number R 308. Department of Civil Engineering, Technical University of Denmark.

Dannemand, M., Johansen, J.B., Furbo, S., 2016a. Solidification behavior and thermal conductivity of bulk sodium acetate trihydrate composites with thickening agents and graphite. Sol. Energy Mater. Sol. Cells 145, 287-295. doi:10.1016/j.solmat.2015.10.038

Dannemand, M., Johansen, J.B., Kong, W., Furbo, S., 2016b. Experimental investigations on cylindrical latent heat storage units with sodium acetate trihydrate composites utilizing supercooling. Appl. Energy 177, 591-601. doi:10.1016/j.apenergy.2016.02.038

Dannemand, M., Kong, W., Fan, J., Johansen, J.B., Furbo, S., 2015b. Laboratory Test of a Prototype Heat Storage Module Based on Stable Supercooling of Sodium Acetate Trihydrate. Energy Procedia 70, 172181. doi:10.1016/j.egypro.2015.02.113

Dannemand, M., Schultz, J.M., Johansen, J.B., Furbo, S., 2015c. Long term thermal energy storage with stable supercooled sodium acetate trihydrate. Appl. Therm. Eng. 91, 671-678. doi:10.1016/j.applthermaleng.2015.08.055 
Furbo, S., Fan, J., Andersen, E., Chen, Z., Perers, B., 2012. Development of seasonal heat storage based on stable supercooling of a sodium acetate water mixture. Energy Procedia 30, 260-269. doi:10.1016/j.egypro.2012.11.031

Furbo, S., Svendsen, S., 1977. Report on heat storage in a solar heating system using salt hydrates. Report no. 70. Thermal Insulation Laboratory, Technical University of Denmark. (BOOK).

G.F.S., 1922. Latent heat of fusion. J. Franklin Inst. 193, 656. doi:10.1016/S0016-0032(22)90585-X

Garay Ramirez, B.M.L., Glorieux, C., Martin Martinez, E.S., Flores Cuautle, J.J. a, 2013. Tuning of thermal properties of sodium acetate trihydrate by blending with polymer and silver nanoparticles. Appl. Therm. Eng. 61, 838-844. doi:10.1016/j.applthermaleng.2013.09.049

Haillot, D., Goetz, V., Py, X., Benabdelkarim, M., 2011. High performance storage composite for the enhancement of solar domestic hot water systems. Part 1: Storage material investigation. Sol. Energy 85, 1021-1027. doi:10.1016/j.solener.2011.02.016

Haillot, D., Nepveu, F., Goetz, V., Py, X., Benabdelkarim, M., 2012. High performance storage composite for the enhancement of solar domestic hot water systems. Part 2: Numerical system analysis. Sol. Energy 86, 64-77. doi:10.1016/j.solener.2011.09.006

Helden, W. van, 2013. COMTES: Combined development of compact seasonal thermal energy storage technologies. RHC Conf.

Hong, H., Kim, S.K., Kim, Y.S., 2004. Accuracy improvement of T-history method for measuring heat of fusion of various materials. Int. J. Refrig. 27, 360-366. doi:10.1016/j.ijrefrig.2003.12.006

Hong, H., Park, C.H., Choi, J.H., Peck, J.H., 2003. Improvement of the T-history Method to Measure Heat of Fusion for Phase Change Materials. Int. J. Air-Conditioning Refrig. 11, 32-39.

Hu, P., Lu, D.J., Fan, X.Y., Zhou, X., Chen, Z.S., 2011. Phase change performance of sodium acetate trihydrate with AIN nanoparticles and CMC. Sol. Energy Mater. Sol. Cells 95, 2645-2649. doi:10.1016/j.solmat.2011.05.025

Höhne, G., Hemminger, W., Flammersheim, H.J., 2003. Differential Scanning Calorimetry. Springer.

K. Kauffman, Pan, Y., 1972. Thermal Energy Storage in Sodium Sulfate Decahydrate Mixtures. University of Pennsylvania.

Kimura, H., Kai, J., 1985. Phase change stability of sodium acetate trihydrate and its mixtures. Sol. Energy 35, 527-534. doi:10.1016/0038-092X(85)90121-5

Kousksou, T., Bruel, P., Jamil, a., El Rhafiki, T., Zeraouli, Y., 2014. Energy storage: Applications and challenges. Sol. Energy Mater. Sol. Cells 120, 59-80. doi:10.1016/j.solmat.2013.08.015

Peck, J.H., Kim, J.J., Kang, C., Hong, H., 2006. A study of accurate latent heat measurement for a PCM with a low melting temperature using T-history method. Int. J. Refrig. 29, 1225-1232. 
doi:10.1016/j.ijrefrig.2005.12.014

Ryu, H.W., Woo, S.W., Shin, B.C., Kim, S.D., 1992. Prevention of supercooling and stabilization of inorganic salt hydrates as latent heat storage materials. Sol. Energy Mater. Sol. Cells 27, 161-172. doi:10.1016/09270248(92)90117-8

Xu, J., Wang, R.Z., Li, Y., 2013. A review of available technologies for seasonal thermal energy storage. Sol. Energy 103, 610-638. doi:10.1016/j.solener.2013.06.006

Yang, S., Tao, W., 1998. Heat transfer, 3rd ed. Higher Education Press, Beijing.

Yinping, Z., Yi, J., Yi, J., 1999. A simple method, the -history method, of determining the heat of fusion, specific heat and thermal conductivity of phase-change materials. Meas. Sci. Technol. 10, 201-205. doi:10.1088/0957-0233/10/3/015

Zalba, B., Marin, J.M., Cabeza, L.F., Mehling, H., 2003. Review on thermal energy storage with phase change: materials, heat transfer analysis and applications. Appl. Therm. Eng. 23, 251-283. doi:10.1016/s13594311(02)00192-8 